\title{
Terahertz Detection of Halogen Additive-Containing Plastics
}

\section{Tadao Tanabe ${ }^{1 *}$, Yuki Makino², Akio Shiota ${ }^{2}$, Mariya Suzuki', Ryo Tanuma², Masafumi Miyajima3 ${ }^{3}$ Noriyuki Sato ${ }^{4}$, Yutaka Oyama²}

\author{
${ }^{1}$ Department of Engineering and Design, Shibaura Institute of Technology, Tokyo, Japan \\ ${ }^{2}$ Department of Materials Science, Tohoku University, Sendai, Japan \\ ${ }^{3}$ Bosch Corporation, Shibuya, Tokyo, Japan \\ ${ }_{4}^{4}$ Industrial Technology Institute, Miyagi Prefectural Government, Sendai, Japan \\ Email: ^tanabet@sic.shibaura-it.ac.jp
}

How to cite this paper: Tanabe, T., Makino, Y., Shiota, A., Suzuki, M., Tanuma, R., Miyajima, M., Sato, N. and Oyama, Y. (2020) Terahertz Detection of Halogen Additive-Containing Plastics. Optics and Photonics Journal, 10, 265-272. https://doi.org/10.4236/opj.2020.1012025

Received: November 17, 2020

Accepted: December 11, 2020

Published: December 31, 2020

Copyright (c) 2020 by author(s) and Scientific Research Publishing Inc. This work is licensed under the Creative Commons Attribution International License (CC BY 4.0).

http://creativecommons.org/licenses/by/4.0/

\begin{abstract}
Terahertz $(\mathrm{THz})$ waves are transparent with respect to non-polar substances, such as plastics. The refractive index at $\mathrm{THz}$ frequencies and the specific spectral features of plastic materials, such as polypropene (PP), polyethylene $(\mathrm{PE})$, polyvinyl alcohol (PVC) and polyethylene terephthalate (PET) can be used to discriminate waste plastics into each material regardless of color. This is important since colored plastic cannot be identified by the present method of near-infrared (NIR) reflection spectroscopy due to absorption of NIR light by the coloring. In addition, the $\mathrm{THz}$ refractive index of acrylonitrile butadiene styrene $(\mathrm{ABS})$ increases in proportion to the content of bromine $(\mathrm{Br})$, which can be used to quantitatively evaluate the presence of halogen additives in waste plastic. We show that the non-contact $\mathrm{THz}$ identification of materials and additives in plastics can be an effective method for sorting plastic waste. Safe \& efficient waste management is one of the most urgent social requirements for smart city innovation.
\end{abstract}

\section{Keywords}

Terahertz Sorting, Plastic Waste, Halogen Additive

\section{Introduction}

At present, the status of plastic waste recycling in Japan is that $56 \%$ of plastic waste generated in 2018 was treated by thermal recycling, $23 \%$ by material recycling and $4 \%$ by chemical recycling, with the remaining $16 \%$ untreated [1]. Large quantities of plastic waste are produced from packaging containers [2], elec- 
tronic devices [3] and vehicles [4]. The separation of plastic wastes is usually performed based on their differences in specific gravity and in their near infrared reflectivity. In material and chemical recycling, plastic wastes are decomposed to raw materials, but it is difficult to discriminate each kind of material. Furthermore, commercial plastics contain bromine for fire resistance. Harmful chemicals such as brominated dioxins can be generated during the recycling process. Therefore, it is required to detect and separate halogen additive-containing plastics.

Plastic materials are frequently identified using near infrared reflectivity are then separated by an air jet. But colored plastics cannot be sorted in this way since near infrared light is absorbed by the color. Therefore, Terahertz (THz) evaluation is expected to be useful to identify plastic materials. $\mathrm{THz}$ light is an electromagnetic wave that is located between radio waves and infrared, with a frequency in the range $0.1-10 \mathrm{THz}$. THz light has the property of high permeability for non-polar substances, so it is available for non-destructive diagnosis [5]-[12]. Also, it can be expected to be available for use regardless of color. Besides, $\mathrm{THz}$ light has low quantum photon energy, so that it is safe for human tissues. Our group has created a database of $\mathrm{THz}$ permeability characteristics for industrial materials and successfully constructed non-destructive $\mathrm{THz}$ diagnosis of metals in building concrete [13] as well as for insulated electronic cable [14]. For the $\mathrm{THz}$ identification of plastic paste, this study investigates the $\mathrm{THz}$ refractive index and spectral features of single plastic materials and bromine additive-containing plastics. The $\mathrm{THz}$ refractive index and spectra were measured for polypropene (PP), polyethylene (PE), polyvinyl alcohol (PVC), colored polyethylene terephthalate $(\mathrm{PET})$, and bromine $(\mathrm{Br})$ additive-containing acrylonitrile butadiene styrene (ABS), which is used as $\mathrm{THz}$ spectral library for discrimination of waste plastic.

\section{Experimental}

Figure 1 indicates a schematic diagram of experimental procedure between $\mathrm{THz}$ spectral library and $\mathrm{THz}$ applications for discrimination of waste plastic plastics and evaluation of additive. For $\mathrm{THz}$ spectral library, $\mathrm{THz}$ refractive index and

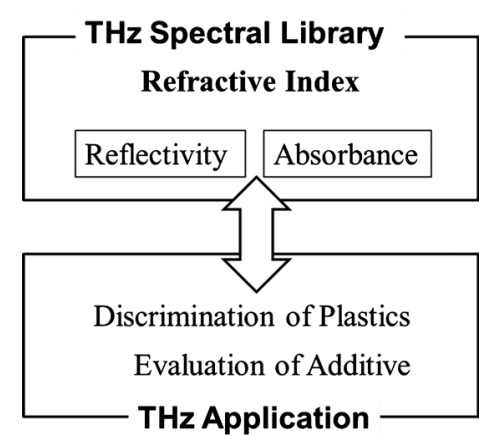

Figure 1. Schematic diagram of experimental procedure between $\mathrm{THz}$ Spectral library and $\mathrm{THz}$ applications for plastics. 
spectrum of plastic can be measured by using $\mathrm{THz}$ time-domain spectroscopy (THz-TDS) and GaP THz Spectrometer, respectively. THz spectrum has information of reflectivity and absorbance, which are effective for practical $\mathrm{THz}$ application.

\subsection{Plastic Samples}

Plastic plates of PE, PP, PVC, PET and ABS were used in this study. Their thickness was $0.5-2 \mathrm{~mm}$. ABS plates with various bromine contents were fabricated as a halogen additive-containing plastic. To compare with the additive composition, PE plates were also fabricated with various contents of carbon black. Colored PET plates were commercially prepared as black, white, and clear.

\subsection{THz Time-Domain Spectroscopy (THz-TDS) [15] [16] [17]}

The optical configuration of THz-TDS was as follows. A femto-second pulse from Ti:Sapphire laser was split into pump light and probe light by a beam splitter and the pump light is introduced to the $\mathrm{THz}$ generating device and probe light guided to the $\mathrm{THz}$ detection device, where each device is a low-temperature grown GaAs photoconductive antenna. The time delay of THz pulse through the plastic sample can be detected by sweeping the delay. By calculating the transmitted $\mathrm{THz}$ pulse shape and phase delay with Fourier transform it is possible to obtain the refractive index of sample in $\mathrm{THz}$ region. The refractive index is averaged in the frequency range of 0.2 to $0.7 \mathrm{THz}$.

\subsection{GaP THz Spectrometer [18]}

Phonon-polaritons in $\mathrm{GaP}$ crystals can afford $\mathrm{THz}$ wave generation in a widely tunable frequency range from $1 \mathrm{THz}$ to $4 \mathrm{THz}$. We have realized a $\mathrm{THz}$ wave signal generator as well as $\mathrm{THz}$ spectrometer. The GaP signal generator uses Cr:Forsterite lasers for both the pump source and signal source.

\subsection{Fabrication of Bromine Additive-Containing Plastics}

Bromine additive-containing $\mathrm{ABS}$ samples were fabricated by the injection molding of ABS (Cevian V-320SF, Daicel) and flame-retardant ABS (FR-ABS, Cevian V-SER2, Daicel). The mixing rate of natural ABS and FR-ABS is shown in Table 1. In this injection molding process, the material is heated and then extruded into a mold by a screw feed. Each material was molded with a resin temperature of $210^{\circ} \mathrm{C}$ and a mold temperature of $45^{\circ} \mathrm{C}$, respectively. The content

Table 1. Details of halogen additive-containing ABS plastics.

\begin{tabular}{cccc}
\hline FRABS conten $\mathrm{t}(\%)$ & $\mathrm{Br}$ (mass \%) & $\mathrm{Sb}$ (mass \%) & $\mathrm{Cl}$ (mass \%) \\
\hline 0 & 0 & 0 & 0 \\
33 & 1.5 & 0.28 & 0.16 \\
66 & 3.4 & 0.81 & 0.26 \\
100 & 6.1 & 1.7 & 0.44 \\
\hline
\end{tabular}


of halogen-based flame retardants and Antimony measured by X-ray fluorescence (XRF) is as shown in Table 1. Also, carbon black doped PE plates were fabricated with various ratios of HDPE (Novatec HD HJ260, Japan polyethylene Corporation) and HDPE/carbon black master batch composite (Japan polyethylene Corporation) using the same method. The master batch has a 20 magnitude black color.

\section{Results and Discussion}

\subsection{Dependence of the THz Refractive Index on Plastic Materials}

Figure 2 shows the dependency of the $\mathrm{THz}$ refractive index on the specific gravity of the plastic samples, where the specific gravity is evaluated for each sample by the Archimedes method with water or ethanol. It is found that a linear relationship exists between the specific gravity and the refractive index, where the slope is 0.45 . This result suggests that non-contact $\mathrm{THz}$ evaluation can separate the plastic waste of PP, PE, ABS, PET and PVC into each material based on its refractive index. As a discriminating component of plastic material, this evaluation can be applied for micro-plastics using $\mathrm{THz}$ wavelength, but which is affected by Rayleigh scattering with particle size [19].

\subsection{THz Spectra of Plastic Materials}

$\mathrm{THz}$ spectra of plastic samples are shown in Fig. 3. Based on the difference between their $\mathrm{THz}$ spectral characteristics, plastic materials can be identified even for colored plastics. PP has the property of high permeability over a wide frequency range. PE has strong absorption band around $2.2 \mathrm{THz}\left(73 \mathrm{~cm}^{-1}\right)$, which is attributed to the $B_{1 u}$ translational lattice vibration mode of PE [20]. Polarization $\mathrm{THz}$ measurements are also helpful for the non-destructive diagnosis of mechanical deformation in polymer [21]. PVC shows a higher transparency at lower frequencies and a lower transparency in higher frequency, respectively. PET samples have lower transmission characteristics even in the lower frequency region, regardless of color. As shown in Figure 3, the $\mathrm{THz}$ spectral features of PP, PE, PVC can be used to discriminate waste plastics into each material. An

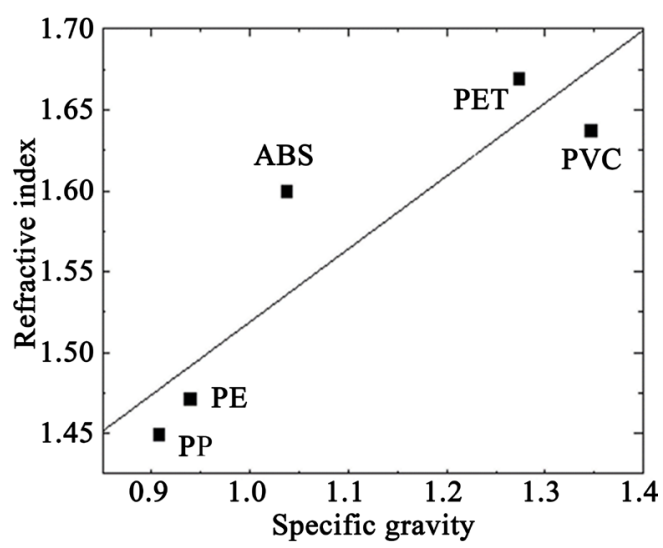

Figure 2. Dependence of the $\mathrm{THz}$ refractive index on the specific gravity. 
imaging system of $300-350 \mathrm{GHz}$ has been realized for sorting black plastics [22].

\subsection{Dependence of ABS THz Refractive Index on Br Content}

Figure 4 shows the refractive index of bromine additive-containing ABS samples versus the bromine content. The refractive index is constant over the frequency range of 0.2 to $0.7 \mathrm{THz}$. The horizontal axis indicates the mass\% of bromine as measured by XRF. It is found that the refractive index $n_{A B S}$ increases linearly with the bromine content $X_{B D}$ which enables us to evaluate the presence of halogen additives in waste plastic by the following equation:

$$
n_{A B S}=0.0048 x_{B r}+1.634
$$

The detection limit considered from the stability of THz measurement is 0.5 mass $\%$ due to the signal/noise ratio of the measurement.

\subsection{THz Refractive Index of PE with Various Contents of Carbon Black}

Figure 5 shows the $\mathrm{THz}$ refractive index of $\mathrm{PE}$ samples with various contents of

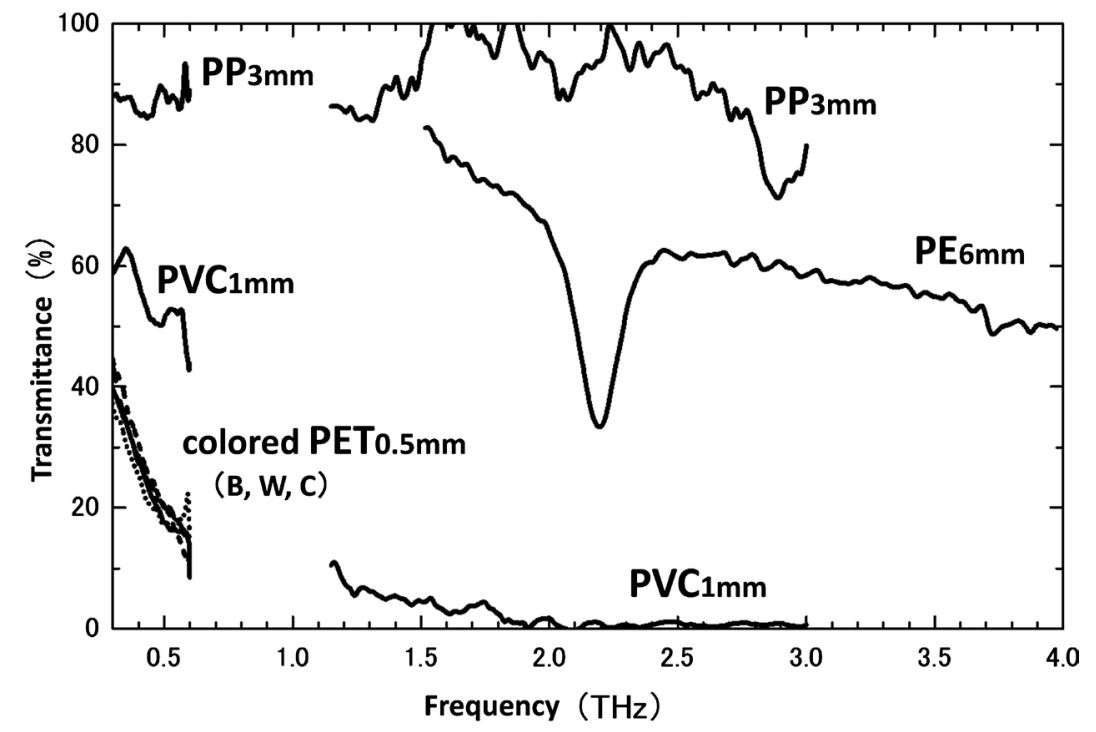

Figure 3. THz spectra of plastic samples.

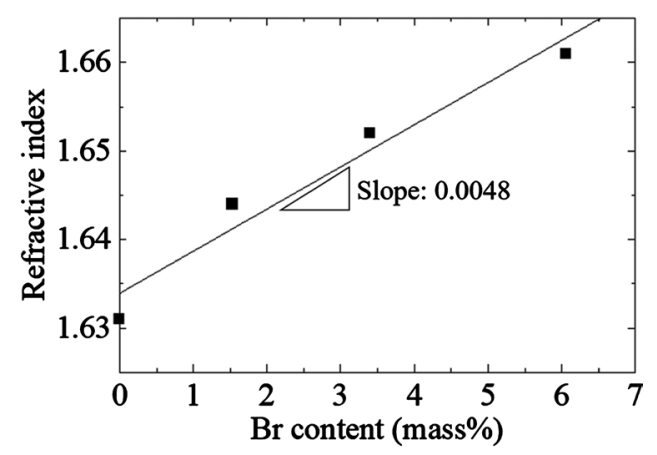

Figure 4. Dependence of $\mathrm{THz}$ refractive index on the $\mathrm{Br}$ content for ABS plastic. 


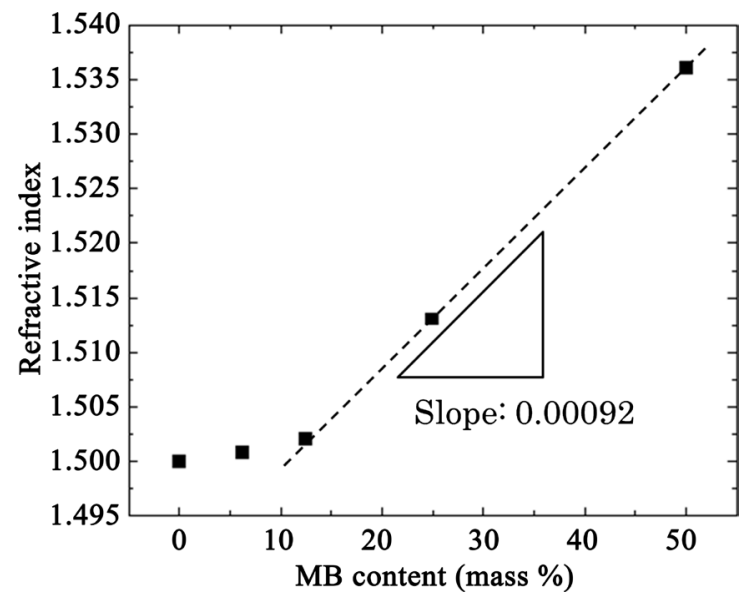

Figure 5. THz refractive index of PE mixed with HDPE/carbon black master batch (MB).

carbon black, which were constant and averaged over the frequency range of 0.2 to $0.7 \mathrm{THz}$. The horizontal axis indicates the mass\% of the HDPE/carbon black master batch $(\mathrm{MB})$ from the fabrication process. The refractive index is almost constant below 10 mass \% content of this MB. As shown in Figure 5, over the 10 mass \%, the slope of refractive index $n_{P E}$ with MB content $x_{M B}$ is 0.00092 , which is fifth smaller than that of $n_{A B S}$ with $x_{B r}$. These results indicate that bromine has a more sensitive influence on the $\mathrm{THz}$ refractive index compared to carbon black as an additive.

\section{Conclusion}

$\mathrm{THz}$ properties of single plastic materials and bromine additive-containing plastics were investigated in order to develop a $\mathrm{THz}$ identification technique for plastic waste. Refractive indexes were measured for PE, PP, PVC, PET and ABS in the frequency region of $0.2-0.7 \mathrm{THz}$, for which a linear relationship was confirmed between the specific gravity and the refractive indexes. The THz spectra of these plastic samples show distinguishable properties. The refractive index of $\mathrm{ABS}$ plastic is also increased as a function of $\mathrm{Br}$ content. Based on the different properties of plastic samples, $\mathrm{THz}$ radiation can be used successful to distinguish between plastic materials and identify halogen additive-containing materials within waste plastics.

\section{Acknowledgements}

This research was supported by JST (Japan Science and Technology Agency)-SCORE program in 2019.

\section{Conflicts of Interest}

The authors declare no conflicts of interest regarding the publication of this paper.

\section{References}

[1] Plastic Waste Management Institute, Report 2018. http://www.pwmi.or.jp 
[2] Sobhani, Z., et al. (2020) Microplastics Generated When Opening Plastic Packaging. Scientific Reports, 10, Article No. 4841. https://doi.org/10.1038/s41598-020-61146-4

[3] Choi, Y., Choi, H. and Rhee, S. (2020) Estimation on Hazardous Characteristics of the Components from Linear Type of End-of-Life Light-Emitting Diode Lamps. Journal of Material Cycles and Waste Management, 22, 307-314. https://doi.org/10.1007/s10163-019-00913-6

[4] Yu, J., Wang, H.Y., Sosuke, T.K., Serrona, K.R.B., Fan, G. and Erdenedalai, B. (2017) Environmental Impacts of Road Vehicles: Past, Present and Future. The Royal Society of Chemistry, London, 174-213.

[5] Hu, B.B. and Nuss, M.C. (1995) Imaging with Terahertz Waves. Optics Letters, 20, 1716-1719. https://doi.org/10.1364/OL.20.001716

[6] Koch, M., Hunsche, S., Schumacher, P., Nuss, M.C., Feldmann, J. and Fromm, J. (1998) THz-Imaging: A New Method for Density Mapping of Wood. Wood Science and Technology, 32, 421-427. https://doi.org/10.1007/BF00702799

[7] Mittleman, D.M., Gupta, M., Neelamani, R., Baraniuk, R.G., Rudd, J.V. and Koch, M. (1999) Recent Advances in Terahertz Imaging. Applied Physics B, 68, 1085-1094. https://doi.org/10.1007/s003400050750

[8] Ferguson, B. and Zhang, X.C. (2002) Materials for Terahertz Science and Technology. Nature Materials, 1, 26-33. https://doi.org/10.1038/nmat708

[9] Kawase, K., Ogawa, Y., Watanabe, Y. and Inoue, H. (2003) Non-Destructive Terahertz Imaging of Illicit Drugs Using Spectral Fingerprints. Optics Express, 11, 2549-2554. https://doi.org/10.1364/OE.11.002549

[10] Nishizawa, J. (2004) Development of $\mathrm{THz}$ Wave Oscillation and Its Application to Molecular Sciences. Proceedings of the Japan Academy Ser. B, 80, 74-81. https://doi.org/10.2183/pjab.80.74

[11] Tonouchi, M. (2007) Cutting-Edge Terahertz Technology. Nature Photonics, 1, 97-105. https://doi.org/10.1038/nphoton.2007.3

[12] Naftaly, M., Vieweg, N. and Deninger, A. (2019) Industrial Applications of Terahertz Sensing: State of Play. Sensors, 19, 4203. https://doi.org/10.3390/s19194203

[13] Oyama, Y., Zhen, L., Tanabe, T. and Kagaya, M. (2009) Sub-Terahertz Imaging of Defects in Building Blocks. NDT\&E International, 42, 28-33. https://doi.org/10.1016/j.ndteint.2008.08.002

[14] Takahashi, S., Hamano, T., Nakajima, K., Tanabe, T. and Oyama, Y. (2014) Observation of Damage in Insulated Copper Cables by THz Imaging. NDT\&E International, 61, 75-79. https://doi.org/10.1016/j.ndteint.2013.10.004

[15] Miles, R.E., Harrison, P. and Lippens, D. (2001) Terahertz Sources and Systems. Springer, Dordrecht. https://doi.org/10.1007/978-94-010-0824-2

[16] Siegel, P.H. (2002) Terahertz Technology. IEEE Transactions on Microwave Theory and Techniques, 50, 910-928. https://doi.org/10.1109/22.989974

[17] Mittleman, D. (2003) Sensing with Terahertz Radiation. Spriger, Berlin. https://doi.org/10.1007/978-3-540-45601-8

[18] Suto, K., Sasaki, T., Tanabe, T., Saito, K., Nishizawa, J. and Ito, M. (2015) GaP Terahertz Wave Generator and $\mathrm{THz}$ Spectrometer Using Cr:Forsterite Lasers. Review of Scientific Instruments, 76, Article ID: 123109. https://doi.org/10.1063/1.2140223

[19] Lord Rayleigh, F.R.S. (1879) XXXI. Investigations in Optics, with Special Reference to the Spectroscope. The London, Edinburgh, and Dublin Philosophical Magazine and Journal of Science Series, 5, 261-274.

https://doi.org/10.1080/14786447908639684 
[20] Tasumi, M. and Shimanouchi, T. (1965) Crystal Vibrations and Intermolecular Forces of Polymethylene Crystals. Journal Chemical Physics, 43, 1245. https://doi.org/10.1063/1.1696911

[21] Tanabe, T., Watanabe, K., Oyama, Y. and Seo, K. (2010) Polarization Sensitive THz Absorption Spectroscopy for the Evaluation of Uniaxially Deformed Ultra-High Molecular Weight Polyethylene. NDT\&E International, 43, 329-333. https://doi.org/10.1016/j.ndteint.2010.03.001

[22] Nüßler, D., Pohl, N., Küls, J., Hein, K. and Stein, D. (2014) THz Imaging for Recycling of Black Plastics. GeMiC 2014 German Microwave Conference, Aachen, 1-4. 